\title{
İyileştirici Bir Tebessüm: Mizah
}

\author{
A Therapeutic Smile: Humor

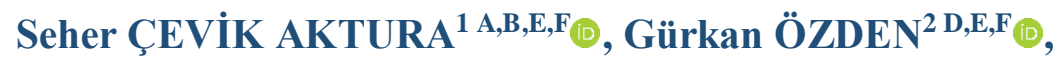 \\ Seyhan ÇITLIK SARITAŞ ${ }^{2}$ E,F,G \\ ${ }^{1}$ İnönü Üniversitesi Hemşirelik Fakültesi, Hemşirelik AD, Malatya, Türkiye \\ ${ }^{1}$ İnönü Üniversitesi Hemşirelik Fakültesi, İç Hastalıkları Hemşireliği AD, Malatya, Türkiye
}

ÖZ

\begin{abstract}
Mizah, olayların komik ve eğlenceli tarafını görmeye çalışmaktır. Mizah, bireylerin bilişsel düzeylerini değiştirerek farklı bir perspektiften düşünmelerine yardımcı olur. Mizah duygusu negatif bir olayla karşılaşılsa bile pozitif bakış açısı geliştirmeyi sağlar. Mizah beden ile ruhu kapsayan ve birbirine bağlayan bir enerji olarak değerlendirilebilir. Literatür, hemşireliğin ilk yıllarından itibaren az da olsa mizah kullanımının varlığını ortaya koymaktadır. Gelişen zamanla beraber hemşirelerin rolleri de değişmekte, mizah stili ve uygulamaları da tedavi ve bakımda kullanılmaya başlanmıştır. Mizahın sağlık üzerinde etkileri olduğuna dair çalışmalar bulunmaktadır. Mizahın bireye fiziksel, duygusal, sosyal ve bilişsel olarak birçok yararı vardır. Hastaların stres ve anksiyetesini azaltmak, baş etme mekanizmalarını daha iyi kullanmalarını sağlamak ve pozitif etkileşimlerini arttırmak amacıyla yapılan espri ve şakaları içermektedir. Mizah eğlenceli karikatürler, hikayeler, komik videolar, hemşirelerin hastalarla iletişim kurarken yaptığı şakalar ve hastane palyaçoları gibi farklı şekillerde olabilmektedir. Hastaya yapılacak girişimler sırasında dikkatini başka yöne çekmek, anksiyetesi yüksek hastayı rahatlatmak ya da hastanın tedaviye, tanıya veya ortama uyumunu arttırmak gibi hemşirelik bakımı alanlarında mizah kullanımı yaygınlaşmalıdır. Bu derlemenin amacı mizahın hemşirelik alanında kullanım amaçlarını incelemektir.
\end{abstract}

Anahtar Kelimeler: Mizah, Hasta, Hemşirelik.

\section{ABSTRACT}

Humor is trying to see the funny and entertaining side of the events. Humor helps individuals to think from a different perspective by changing their cognitive levels. It provides a positive perspective even if a sense of humor is encountered. Humor can be considered as an energy that explains and connects the body and spirit. The literature reveals the existence of a small amount of humor use since the early years of nursing.. With the developing time, the roles of nurses also change, and humor style and practices have started to be used in treatmentand care. There are studies showing that humor has effects on health. Humor has many benefits to the individual physically, emotionally, socially and cognitively. Humor can take different forms such as funny cartoons, stories, funny videos, jokes made by nurses while communicating with patients, and hospital clowns. The use of humor should become widespread in nursing care areas such as distracting attention during interventions on the patient, relieving the patient with high anxiety, or increasing the patient's adaptation to treatment, diagnosis or environment.. The purpose of this review is to examine the uses of humor in nursing.

Key Words: Humor, Patient, Nursing.

\section{GİRİŞ}

Mizah, yüzyıllardır araştırma ve felsefe gibi alanların ilgi konusu olmuş ayrıca gerginliğin azaltılması, pozitif etkileşimin sağlanması ve sosyal birlikteliğin oluşturulması gibi 
tıp alanında da kullanılmaya başlanmıştır (1). Mizah, karşıllaşılan olay ve durumların komik ve eğlenceli taraflarını görebilme yeteneği olarak tanımlanmaktadır (2). Başka bir ifade ile mizah kendisine gülünebilme, komik olma özelliği olan ruh halidir. Mizah duygusu negatif bir olayla karşılaşılsa bile pozitif bakış açısı geliştirmeyi sağlar. Mizah beden ile ruhu kapsayan ve birbirine bağlayan bir enerji olarak değerlendirilebilir (3). Mizah, her türlü toplumsal bağlamda meydana gelen evrensel bir insan faaliyetidir. Kahkaha bile tek başına, kişinin olumlu duygularını ifade etmek ve diğerlerinde olumlu tepkiler uyandırmak için kullanılan bir sosyal iletişim biçimidir (2). Sağlık alanında hastaya yapılacak girişimler sırasında dikkatini başka yöne çekmek, anksiyetesi yüksek hastayı rahatlatmak ya da hastanın tedaviye, tanıya veya ortama uyumunu arttırmak gibi çeşitli amaçlarla kullanılmaya başlanmalıdır. Bu derlemenin amacı mizahın hemşirelik alanında kullanım amaçlarını detaylı olarak incelemektir.

\section{Mizah Kullanımının Tarihçesi}

Literatür, hemşireliğin ilk yıllarından itibaren az da olsa mizah kullanımının varlı̆̆ını ortaya koymaktadır. Florence Nightingale tarafından benimsenen "profesyonel" tavır, hemşirelerin daha az gülmelerine neden olmuştur. Kendisinin mizahi yönünün güçlü olduğu düşünülmesine rağmen, profesyonel olarak, bu algıya karşı tedbir amacıyla öğrencilere “... ciddi, güvenilir, dürüst, iffetli ve temiz...” olmalarını vurgulayarak çok kısıtlı bir mizah kullanımına işaret etmiştir $(4,5)$. Bunun yanı sıra Nightingale "Hemşirelik Notları" kitabında (1860) "ağrı dolu deneyimlerin üstesinden gerçek bir kahkaha ile daha iyi gelinebileceğini" belirtmiştir (6). 1940'larda, 50'lerde ve 60'larda literatürde ara sira "hemşirelik mizahı" olduğuna dair kanıtlar vardır, ancak çoğunlukla öğrenci hemşirelerin karikatürlerle ya da hemşirelerin karşılaştıkları sıkıntılar karşısında fikralarla ve içinde olunan durumla eğlenmeleri şeklindedir. Fakat bu süreçte mizah hemşirelik mesleğinin işlevsel bir aracı olarak görülmemiştir. Hemşirelik mesleğinin mizahı ciddiye aldığına dair ilk kanıt 1960'ların ortalarında ortaya çıkmıştır. Hemşirelik ve hemşirelik bakımı uygulamalarıyla, mizah kavramına ilişkin ilk güvenilir araştırma, hemşirelik eğitimi müfredatına zihinsel sağlık içeriğini entegre etmek için kullanılmaya başlanmıştır. Hemşire araştırmacı Vera Robinson, hastalıkların yarattığı stres ile başa çıkmayı incelemek amacıyla yaptığı çalışmalarda mizah kavramını incelemeyi seçmiştir (4). 1970'lerin sonuna doğru ise mizah sağlık alanı uygulamaların kullanılabilecek uygun bir yöntem/araç olarak görülmeye başlanmıştır. Seksenli yıllarda kişinin kendini çok ciddiye almaması ile ilgili çalışmalar yapıllmıştır. 1995 yılında ise Buxman hemşirelik alanında terapötik mizahın uygulanması ile ilgili araştırma ve denemelerin ilk derlemesini düzenlemiş ve yayınlamıştır. Derlemeye katkısı bulunanların hepsi hemşire olup, odakları ya hemşirelerin kendileri için mizah ya da hasta bakımı için mizahtır (4). 1982 yılında mizah kullanımını teşvik etmek amacıyla "Nurses for Laughter" derneği kurulmuş, sonraki yıllarda "The Association for Applied and Therapeutic Humor (AATH)" adını almıştır. İlk Uluslararası Mizah Konferansı 1976'da Galler'de düzenlenmiştir fakat 1979'da Los Angeles'ta düzenlenen İkinci Uluslararası Mizah Konferansı' na hemşireler katılmıştır $(2,5)$.

II. Dünya Savaşından önce annelik rolü ile özdeşleşen hemşirelik, tıbbi ve teknolojik ilerlemeler ile modern dünyanın özel ve farklı rollerini üstlenmiştir (2). Bu süreçten sonra hemşirelerin rolleri de değişmiş olup, mizah stili ve uygulamaları da tedavi ve bakımda kullanılmaya başlanmıştır. Böylelikle hemşirelik bakımında mizah önem kazanmıştır ve önemli 
bir hemşirelik girişimi olarak kabul edilmeye edilmiştir $(7,8)$. İlk kez hastaların sağlı̆̆ını geliştirmek amacıyla Coser tarafindan kullanılan terapötik mizah günümüzde hemşirelik bakımının bir parçası olmuştur $(2,7)$.

\section{Sağlık Üzerine Etkileri ve Kullanımı}

Mizahın sağlik üzerindeki etkisi teorik olarak Martin ve Gremigni tarafından modellenmiş ve karmaşık bir süreç olduğu vurgulanmıştır $(9,10)$. Mizahi kahkahalar, bilim adamlarının her zaman anlamada zorluk çektiği yaşlanmayan bir olgudur. Bu karmaşıklıklar, mizahın bilişsel, fizyolojik, felsefi ve psikolojik yönlerini içerir. Freud, bireyin cinsellik ve saldırganlık gibi sosyal tabuları ifade etmek için mizah yüklü davranışları bir yol olarak kullandığını açıklamıştır (11). Ziv, mizahın kendi eksikliklerinden kaçınmakla ilgili kaygıyı önlemek için sıklıkla savunma mekanizması olarak kullanıldığını iddia etmiştir (12).

Mizah, birçok etkileşimde sosyalleşmeye ve iletişime izin verir ve genellikle iki boyutta tanımlanır: mizahın uygulanması ve mizah yaratılması. Örneğin, bir kişi iyi bir mizah anlayışına sahip olduğuna dikkat çekerse, bu genellikle kişinin bu niteliklerden birine veya her ikisine sahip olduğu anlamına gelir. Herkes bireysel olarak özgürce gülme potansiyeline sahiptir, ancak bazıları bunu açıklık ve yaratıcılık kapasitelerine bağlı olarak baskılayabilir. Diğerleri ise bir kayıp nedeniyle kederli olmaları, kronik olarak depresyonda olmaları, mizahı anlayamamaları veya genel olarak duygularını kontrol etmeleri ve gizli yaşamaları nedeniyle mizahı kullanmayı uygun görmeyebilirler. Mizah yokluğu, çeşitli yaşam koşullarının bir yan ürünü olarak tanımlanmıştır (13).

Fizyolojik mekanizmalar açısından, kahkahalar kalbin daha hızlı atmasını sağlar, hayati organlara kan akışını arttırır ve beynin kimyasal dengeyi ve vücuttaki hipofizi değiştirmesine neden olan besin maddelerinin dağılımını iyileştirir. Böylelikle endorfin ve dopamin üretebilir. Bunun sonucunda ise depresyonun azaltılması ve pozitif düşünce geliştirilebilir $(14,15)$. Genel olarak mizahın insanların sağlığı ve yaşamındaki faydaları şu şekilde sıralanabilir: refahı destekler; zor ve hoş olmayan durumların üstesinden gelmeye yardımcı olur; rollerini eşitleyerek insanları bir araya getirir; duyguları paylaşmaya yardımcı olur; umut sağlar; rahatlamayı teşvik eder; Doğal öldürücü hücrelerin (NK) aktivitesini artırarak ve immünoglobulin düzeylerini artırarak gerginliği, stresi ve rahatsızlığı azaltır, ağrıya toleransı artırır ve bağışıklık sistemini güçlendirir (16-18). Hemşirelik Girişimleri Sınıflamasına (NIC) göre mizah, hemşirelerin kişinin komik, eğlenceli veya mizahi olanı algılamasına, takdir etmesine ve ifade etmesine, ilişkiler kurmasına, gerginliği gidermesine, öfkesini gidermesine ve başa çıkmayı kolaylaştırmasına yardımcı olan bir girişim olarak tanımlanır (19). Beck'in hemşirelik uygulamalarında mizah kullanımı üzerine yaptığı araştırmada beş tema sunulmaktadır: Mizah zor durumları kolaylaştırır, mizah bağlılık yaratır, mizah etkili bir terapötik iletişim tekniği olabilir, mizah planlanabilir veya kendiliğinden olabilir, mizahı paylaşmak kalıcı etkiler yaratır (7). Mizah ve sağlık arasında hem doğrudan hem de dolaylı bir ilişki mevcuttur, fakat her mizah türü belirli bir araştırma gerektirir ve sağlık üzerinde farklı etkiler gösterir (20). Hemşirenin bakım bağlamında mizah kullanımına ilişkin algıları, mizahın çok kişisel bir şey olduğunu göstermektedir. Bir kişiyi güldüren şey, bir başkasında rahatsızlık ve acıya neden olabilir (16). Bu durum, mizahın sahip olabileceği paradoksal karakteri ortaya koymaktadır, yani bir kişide mizah nedeni olan şey bir başkası için olmayabilir. Bu anlamda 
mizah kullanımı çok yönlü bir olgu olması nedeniyle her duruma uygun olmalıdır (17). Mizah asla hastalara zorlanmamalıdır ve mizah kullanan sağlık profesyonellerine, hastaların ve aile üyelerinin trajik haberlerle karşı karşıya olabilecekleri veya sevilen birinin kaybına üzülüyor olabilecekleri konusunda dikkatli olmaları öğretilmelidir (22).

Mizah farklı şekillerde olabilmektedir. Eğlenceli karikatürler, hikayeler, komik videolar, hemşirelerin hastalarla iletişim kurarken yaptığ 1 şakalar, hatta bazı ülkelerde doktorların hasta reçetelerine hastane palyaçolarını yazmaları örnek olarak verilebilir (3). Sağlık bakımında mizah ve kahkaha, hastanın ruh halini ve yaşam kalitesini iyileştirmeyi amaçlamaktadır. Hemşireler, hasta bakımında mizah kullanmada geleneksel olarak doktorlardan daha aktif bir rol oynamıştır (21). Bazı hastanelerde, personel ve gönüllüler için mizah kartları ve çeşitli yöntemler kullanılarak hazırlanan resmi mizah programları vardır. Mizah kartları standart hastane kartlarına benzer, bunların yanında hastaları güldürmek için mizahi kitapları, videokasetleri gibi gereçlerde kullanılabilir. Mizah kullanmak ve hastaların gülmesine izin vermek, onları en azından geçici olarak fiziksel acıdan uzaklaştırma potansiyeline sahiptir. Mizah ile ilgili yapılan araştırmaların çoğu çocuk hemşireliğinde yapıldığ1 görülmektedir $(23,24)$. Sağlık hizmetlerinin yanında, mizah ile ilgili uygulamalar pozitif psikoloji alanında kullanılmıştır $(25,26)$. Sağlıkla ilgili çalışmaların bazıları huzurevlerindeki yaşli bireylerle $(27,28)$, kanser hastalarıyla $(29,30)$ ve depresyondaki bireylerle (31) yapılmıştır. Sağlık alanında mizah ve kahkaha kullanma, tedavi sırasında hastaların ve sağlı hizmeti sunucularının öznel iyi oluşlarını ve çevreleri ile ilgili olma potansiyelini arttırır $(32,33)$.

Mizah kanser, hipertansiyon ve inme gibi stres ile yakından ilişkili hastalıkların yönetiminde de kullanılabilir. Mizah ve kahkaha ortamdaki gergin ve soğuk havayı dağıtan bir "buz kırıcı" gibi görev yapar. Örneğin, HIV/AIDS gibi konularda yapılan eğitimler sırasında doğru kullanılan mizah bir bağlama aracı olabilir ve hastaların rahatlamasını sağlayarak öğrenmeyi kolaylaştırır (36,37). Avusturalya'daki bir bakım evinde, 9-12 haftalık süreyle 398 hastaya kahkaha ve mutluluğu arttırmak için komik şarkı ve dans seanslarını içeren palyaço ziyaretleri yapılmıştır. Ziyaretlerden sonra deney grubunun anksiyete ve ajitasyonunda önemli oranda azalma olduğu bulunmuştur (27). Warren ve Spitzer çeşitli ülkelerdeki sağlık kurumlarında kullanılan farklı türdeki hastane palyaçosu uygulamalarını incelemiş ve mizahın yaşlılar ve yaşam sonu bakım hastalarına olumlu etkilerinin yanında, diğer hastalar, sağlık profesyonelleri ve ailelerin üzerinde de pozitif bir etkiye sahip olduğunu vurgulamışlardır (42). Sağlık hizmetlerinde sadece farklı tür palyaçolar değil, aynı zamanda farklı mizah stilleri de kullanılmaktadır (43).

Klinik hemşirelik uzmanlarının yardımı ile yürütülen bir araştırmada 32 hastanın mizah hakkındaki görüşleri 6 ay boyunca haftalık olarak değerlendirilmiştir. Hastalar aldıkları tanıya göre; akciğer kanseri, prostat kanseri, meme kanseri ve inme şeklinde dört odak grubuna ayrılmışlardır. Araştırmanın sonucu hastalar için mizahın anlamlı bir terapötik etkileşim geliştirmede önemli olduğunu ortaya koymuştur (44). Mizah ayrıca hastaların yaşamlarının stres yüklü, zorlayıcı veya istenmeyen durumlar gibi çeşitli yönleriyle ilgili bir başa çıkma mekanizması gibi görünmektedir. Demjen, online bir platformdaki kanserli bireylere ilişkin verileri analiz etmiştir. Analiz sonucunda hastaların kanser ve sebep olduğu komplikasyonlarla başa çıkmak için birçok yaratıcı ve farklı yolla içinde bulundukları durumla dalga geçtiklerini bulduğunu belirtmiştir (40). Terapötik mizahın kanser hastalarına ilişkin etkililiğinin sonuçları 
farklılık göstermektedir; Mizah içeren bir iletişim tekniği olan Smile-Sun tekniğinin bazı hastalarda bağışıklık düzeylerini artırdığı gösterilmişken, bazı hastalarda da mizah çalışmalarının etkisiz olduğu bildirilmiştir. Bu heterojen sonuçların, uygulanan farklı mizah türlerinin bir sonucu olabileceği düşünülmektedir. Bununla birlikte, yaşam kalitesi ölçeklerinden alınan skorların genel olarak pozitif yönde arttığı görülmüş ve mizahın başa çıkma mekanizması olarak kullanılabileceğine dair sonuçlara ulaşılmıştır (45). Ayrıca mizah sadece hastanın stresini azaltmak için değil aynı zamanda hasta yakınları ve sağlık ekibi arasındaki iletişimi pekiştirmek için de kullanılabilmektedir (8). Koç ameliyat öncesi dönemdeki çocukların ve ailelerinin anksiyete düzeylerini incelediği çalışmasında, 7 ile 14 yaş arası 64 çocuk hasta ve ailelerine ameliyattan önce eğitimli palyaço hemşireler tarafindan 5 dakikalık palyaço ziyareti yapılmıştır. Çalışma sonucunda anne ve babaların anksiyete düzeyinde anlamlı düzeyde azalma kaydedilirken, çocukların anksiyete seviyesinde önemli bir farklılık görülmemiştir (41). Linge ve arkadaşlarının yoğun bakımda çalışan 8 hemşire ile yaptıkları araştırmada, hemşireler hem hasta ve yakınları ile hem de diğer çalışanlar ile aralarında mizahı kullandıklarını ifade etmişlerdir. Hemşireler mizah kullanmanın hasta takibi, hasta viziti ve teslimleri sırasında özellikle yararlı olduğunu vurgulamışlardır (38). Ülkemizde ise bakım ve tedavi uygulamalarında mizah kullanımı henüz istenilen seviyede değildir. Tuğut ve Kaya'nın 163 hemşire ile yaptıkları bir çalışmada hemşirelerin sadece \%14.5'nin terapötik mizah hakkında bilgi sahibi olduğu bildirilmiştir (39).

Mizah henüz sağlık hizmetleri alanında tam olarak oturtulamamıştır ve mizahın sağlık hizmetlerinin ayrılmaz bir bileşeni olarak kullanılmasını destekleyen bilimsel eğitimler hala yeterli düzeyde değildir (46). Ek olarak, fiziksel sağlı̆̆n belirli mizah tarzlarıyla ilişkisini inceleyen deneysel araştırmalarda güvenilir kanıtlara ulaşılamamıştır (47). Hasta-hemşire ilişkisinde mizah hastaların zorluklarla yüzleşmelerine, hastalıkları ile başa çıkmalarına ve hayatlarını değiştiren durumları atlatmalarına yardımcı olur. Ancak her bireyin mizahı aynı derecede benimseyip kullanmayacağı da unutulmamalıdır. Nerede kullanılırsa kullanılsın mizah, bireyin kültürel, dini ve bireysel değerleri göz önünde bulundurulmalı ve birey üzerindeki etkileri mutlaka değerlendirilmelidir (3).

\section{SONUÇ}

Farklı sonuçlar olmakla beraber hasta bakımında mizah kullanmanın psikolojik, fizyolojik ve sosyal birçok faydası vardır. Mizah ve kahkaha, hemşireler ve hastalar arasında daha insani, karşılıklı ve samimi bir bağ kuran, içtenlik ve özgünlük sunan doğal duygu ifadeleridir. Hastaların kendi bakımlarına katılması, anksiyetelerinin azaltılması ve pozitif etkileşim düzeylerinin artması sağlanarak karmaşık durumları yönetme ve çözmede oldukça yararlı bir araç olarak kullanılabilir. Ayrıca hastaların baş etme mekanizmalarını daha iyi kullanması sağlanarak daha kaliteli bir bakım almaları sağlanabilir ve memnuniyet düzeyleri arttırılabilir. Mizah eğitim ve kişiselleştirilmiş stratejiler gerektirdiği için hemşireler tarafindan dikkatlice kullanılmalıdır.

\section{Finansal Destek}

Herhangi bir finansal destek bulunmamaktadır. 


\section{Çıkar Çatışması}

Yazarlar arasında çıkar çatışması yoktur.

\section{KAYNAKLAR}

1. Hulse, J.R. (1994). Humor: A nursing intervention for the elderly: Used appropriately, humor can aid in education, reduce stress, and relieve the depersonalization many elderly people feel. Geriatric Nursing, 15(2), 88-90.

2. Buxman, K. (2018). How one mad scientist grasped the profound potential of humor and changed the face of nursing. Humor, 31(2), 329-337.DOI: 10.1515/humor-20180020

3. Koç, S. (2016). The Compassionate Touch in Intensive Care: Humor and Smiling. Aslan, F.E., Olgun, N. Intensive Care Selected Symptoms and Management of Findings. 1st Edition (s. 113-27). Nobel Medical Bookstores, Ankara.

4. Robinson, V. (1995). Humor in nursing: A hysterical perspective. Buxman, K., LeMoine, A. Nursing perspectives on humor. 1st ed.USA: Power Publications.

5. Schwartz, E.A. (2010). Humor and health care: The laughter prescription. 2nd ed. Brockton, MA: Western Schools.

6. Kelly, L. (1981). Dimensions of professional nursing. 4th ed. New York: Macmillan.

7. Beck, C.T. (1997). Humor in nursing practice: a phenomenological study. Int J Nurs Stud, 34(5), 346-352.doi:10.1016/s0020-7489(97)00026-6.

8. Aydin, A. (2005) Nursing and humor. Journal of Cumhuriyet University School of Nursing, 9(1):1-5. http://eskidergi.cumhuriyet.edu.tr/makale/1118.pdf

9. Martin, R. (2008). Humor and health in The Primer of Humor Research. Raskin, V.1st ed. (ss.479-522).Berlin: Mouton de Gruyter.

10. Gremigni, P. (2012). Humor and Health Promotion. 1st ed. Hauppage, NY: Nova Science Publishers.

11. Sigmund Freud 1856-1939 (1905). Jokes and their relation to the unconscious / Sigmund Freud; translated from the German and edited by James Strachey. W. W. Norton \& Company.

12. Ziv, A. (1988). Teaching and learning with humor: Experiment and replication. $J$ Exp Educ, 57(1), 5-15.

13. Goldstein, J.,\& Ruch, W. (2018). Paul McGhee and humor research. Humor, 31(2), 169-181.

14. Yun, O.B., Kim, S.J., \& Jung,D. (2015). Effects of a clown-nurse educational intervention on the reduction of postoperative anxiety and pain among preschool children and their accompanying parents in South Korea. J Pediatr Nurs, 30(6), 8999.doi: 10.1016/j.pedn.2015.03.003.

15. Mora, R.R., \& García, M.R. (2008). Therapeutical value of laughter in medicine. Medicina clinica, 131(18), 694-698.doi: 10.1157 / 13129114.

16. Haydon, G., \& Riet, P. Van Der. (2014). A narrative inquiry: How do nurses respond to patients' use of humour? Contemporary Nurse, 46(2), 197-205. https://doi.org/10.5172/conu.2014.46.2.197

17. Sousa, L.M.M., Marques-Vieira, C.M.A., Antunes, A.V., Frade, M. de F.G., Severino, S.P.S., \& Valentim, O.S. (2019). Humor intervention in the nurse-patient interaction. Revista Brasileira de Enfermagem, 72(4), 1078-1085. https://doi.org/10.1590/00347167-2018-0609 
18. Tremayne, P. (2014). Using humour to enhance the nurse-patient relationship. Nursing Standard, 28(30), 37-40. https://doi.org/10.7748/ns2014.03.28.30.37.e8412

19. Butcher, H. K., Bulechek, G. M., Dochterman, J. M., \& Wagner, C. M. (2018). Nursing interventions classification (NIC). St. Louis: Elsevier.

20. Simpson, J.M., \& Snow, S.J. (2017). Why We Should Try to Get the Joke: Humor, Laughter, and the History of Healthcare. The Oral History Review, 44(1), 7793.doi:10.1093/ohr/ohw110.

21. Beach, W.A., \& Prickett, E. (2017). Laughter, humor, andcancer: Delicate moments and poignant interactional circumstances. Health communication, 32(7), 791-802. doi:10.1080/10410236.2016.1172291

22. Grant, W.M. (2017). Humor in Medicine: A Literature Review of Humor's Potential Therapeutic Value in Health Care. https://scholarworks.uark.edu/psycuht/11.

23. Sridharan, K., \& Sivaramakrishnan, G. (2017). Therapeutic clowns in pediatrics: a systematic review and meta-analysis of randomized controlled trials-corrigendum. Eur J Pediatr, 176(2), 289-289.doi:10.1007/s00431-016-2832-5.

24. Perktaş, E., \& Özmert, E. (2017). An assessment on the reduction of children's hospital anxiety: The hospital clown project. Journal of Child Health and Diseases, 60(3), 8387.

25. Ruch, W., \& Hofmann, J. (2017). Fostering humour. Ruch, W., Hofmann, J. Positive psychology interventions in practice. 1st ed. (ss. 65-80). Springer, Cham.

26. Ruch, W., \& McGhee, P.E. (2014). Humor intervention programs. Schueller S, Parks A. Handbook of Positive Psychological Interventions. 1st ed. Oxford: Wiley-Blackwell.

27. Goodenough, B., Low, L.F., Casey, A.N., Chenoweth, L., Fleming, R., Spitzer, P., et al. (2012). Study protocol for a randomized controlled trial of humor therapy in residential care: the Sydney Multisite Intervention of Laughter Bosses and Elder Clowns (SMILE). Int Psychogeriatr, 24(12), 2037-2044. doi:10.1017/s1041610212000683.

28. Kim, S.H., Kook, J.R., Kwon, M., Son, M.H., Ahn, S.D., \& Kim, Y H. (2015). The effects of laughter therapy on mood state and self-esteem in cancer patients undergoing radiation therapy: a randomized controlled trial. JACM, 21(4), 217-222.doi: $10.1089 / \mathrm{acm} .2014 .0152$

29. Itami, J. (2000). A Trial Psychosomatic Treatment for Cancer: Meaningful Life Therapy. Journal of International Society of Life Information Science, 18(1), 162171.doi: 10.18936/islis.18.1_162.

30. Venter, M., Venter, C., Botha, K., \& Strydom, M. (2008). Cancer patients' illness experiences during a group intervention. $J$ Psychol Afr, 18(4), 549-560.doi: 10.1080/14330237.2008.10820234.

31. Shahidi, M., Mojtahed, A., Modabbernia, A., Mojtahed, M., Shafiabady, A., Delavar, A., et al. (2011). Laughter yoga versus group exercise program in elderly depressed women: a randomized controlled trial. Int J Geriatr Psychiatry, 26(3), 322-327.doi: $10.1002 /$ gps. 2793.

32. Martin, R.A. (2019). Humor. Gallagher, MW., Lopez, SJ. Positive psychological assessment: A handbook of models and measures. 1st ed.(305-316).

33. Ruch, W., Proyer, R.T., \& Weber, M. (2010). Humor as a character strength among the elderly. Zeitschrift für Gerontologie und Geriatrie, 43(1), 13-18.doi:10.1007/s00391009-0090-0.

34. Kuiper, N., Kirsh, G., \& Maiolino, N. (2016). Identity and intimacy development, humor styles, and psychological well-being. Identity, 16(2), 115-125.doi: 10.1080/15283488.2016.1159964

35. Maiolino, N., \& Kuiper, N. (2016). Examining the impact of a brief humor exercise on psychological well-being. Transl Issues Psychol Sci, 2(1), 4.doi: 10.1037/tps0000065. 
36. Zorlu, H.,\& Gündüz, Ö. (2019). Psikoterapide Mizah. JCBPR,8(3), 190-199.

37. Woodbury-Farina, M.A., \& Antongiorgi, J.L. (2014). Humor. Psychiatricclinics, 37(4), 561-578.

38. Linge-Dahl, L.M., Heintz, S., Ruch, W., \& Radbruch, L. (2018). Humor assessment and interventions in palliative care: A systematic review. Frontiers in psychology,19(9):112. doi: 10.3389/fpsyg.2018.00890890.

39. Tuğut, N., \& Kaya, D. (2017). The Relationship Between Nurses' Using Therapeutic Humor and Problem Solving Skills. Dokuz Eylul University E-Journal of Nursing Faculty, 10(3),

131-136. http://www.deuhyoedergi.org/index.php/DEUHYOED/article/view/364

40. Demjen, Z. (2016). Laughing at cancer: Humour, empowerment, solidarity and coping online. Journal of Pragmatics, 101(1), 18-30.doi:10.1016/j.pragma.2016.05.010.

41. Koç, S. (2011). Determining the effect of hospital clowns on anxiety levels of children and their parents in the pre-operative period. Journal of Education and Research in Nursing, 8(3), 31.https://www.journalagent.com/kuhead/pdfs/KUHEAD_8_3_26_31.pdf

42. Warren, B., \& Spitzer, P. (2011). Laughing to longevity - the work of elder clowns. The Lancet, 378(9791), 562-563.doi:10.1016/s0140-6736(11)61280-4.

43. Ruch, W., Heintz, S., Platt, T., Wagner, L., \& Proyer, R. T. (2018). Broadening humor: comic styles differentially tap into temperament, character, and ability. Frontiers in Psychology, 9, 6.doi:10.3389/fpsyg.2018.00006.

44. McCreaddie, M., \& Payne, S. (2014). Humour in health-care interactions: a risk worth taking. Health Expectations, 17(3), 332-344. https://doi.org/10.1111/j.13697625.2011.00758.x

45. Bennett, P.N., Parsons, T., Ben-Moshe, R., Weinberg, M., Neal, M., Gilbert, K., et al. (2014). Laughter and Humor Therapy in Dialysis. Seminars in Dialysis, 27(5), 488493. https://doi.org/10.1111/sdi.12194

46. Sanchez, J.C., Echeverri, L.F., Londono, M.J., Ochoa, S.A., Quiroz, A.F., Romero, C.R., et al. (2017). Effects of a Humor Therapy Program on Stress Levels in Pediatric Inpatients. Hospital Pediatrics, 7(1), 46-53. https://doi.org/10.1542/hpeds.2016-0128

47. Mendiburo-Seguel, A., Paez, D., \& Martinez-Sanchez, F. (2015). Humor styles and personality: A meta-analysis of the relation between humor styles and the Big Five personality traits. Scandinavian Journal of Psychology, 56(3), 335-340. https://doi.org/10.1111/sjop.12209 